\title{
O ccurrence of Cryptosporidium (Apicomplexa, Cryptosporidiidae) in Crotalus durissus terrificus (Serpentes, Viperidae) in Brazil
}

\author{
Andréa Satie Matsubara Karasawa, Reinaldo José da Silva/ ${ }^{+}$, Luciene Maura Mascarini, \\ Thomaz Henrique Barrella*, Carlos Alberto de Magalhães Lopes*
}

Departamento de Parasitologia, Instituto de Biociências, U nesp, Distrito de Rubião Júnior, s/n0, 18618-000 B otucatu, SP, B rasil

* Centro de Estudos de Venenos e A nimais Peçonhentos, Unesp, B otucatu, SP, B rasil

The objective of the present study was to investigate the prevalence of Cryptosporidium (Apicomplexa, Cryptosporidiidae) in the snake Crotalus durissus terrificus (Serpentes, Viperidae). Fifty animals were evaluated for the presence of oocysts of Cryptosporidium sp. at the time of arrival and 30 and 60 days later. Intestinal washings with saline solution ( $1 \%$ body weight), fecal samples, and organ scrapings were collected during the study. 0 ocysts were concentrated by an ether-phosphate-buffer ed saline sedimentation technique and then separated by a density gradient centrifugation technique. Smears were made with the sediment and submitted to modified acid-fast and auramine-rhodamine staining. Cryptosporidium-positive smears were used as controls for the experimental findings. The overall prevalence of Cryptosporidium sp. 0ocysts was 14\%. Among the positive snakes, oocysts were detected only in the intestinal washing in two specimens, only in the feces in four specimens, and in both materials at least once in one specimen. The positive snakes were predominantly from Santa M aria da Serra city State of São Paulo $(57.1 \%)$. We also observed that all of the examinations that presented positive results were obtained at least 27 days after the capture of the animals.

Keywords: Cryptosporidium - Crotalus durissus terrificus - snakes - Brazil

Cryptosporidiosis is currently a topic of great worldwide interest in terms of hygiene and health because it can be detected in different hosts, including man, other mammals, birds, reptiles, amphibians, and fish (Fayer \& Ungar 1986, Cranfield \& G raczyk 1996).

The etiological agent is a protozoan of the genus Cryptosporidium that colonizes the mucous membranes of the gastric or intestinal epithelium, sometimes causing clinical signs or subclinical infection. Several studies have been published on the occurrence of cryptosporidiosis in snakes (Fayer et al. 1995, G raczyk \& Cranfield 1996, 1998, Graczyk et al. 1996a,b, 1998a,b,c). Infections described in B oa, Elaphe, and C rotalus species suggest that all snakes species may serve as hosts. Easily stressed species, such as rattlesnakes, seem to have a higher infection-rate.

There are studies on the prevalence of Cryptosporidium sp. in B razilian snakes such as Boa constrictor, Corallus caninus, and Epicrates cenchria cenchria, but no references are available for venomous snakes. Thus, the objective of the present study was to investigate the prevalence of Cryptosporidium in C. $d$. terrificus.

\section{MATERIALSAND METHODS}

The study was conducted on $C$. $d$. terrificus snakes from B otucatu, State of São Paulo, B razil, recently captured and donated to the Center for the Study of Venoms and

Financial support: Fundação de A mparo a Pesquisa do Estado de São Paulo (F apesp)

${ }^{+}$Corresponding author. Fax: +55-14-68213744. E-mail: reinaldo@ibb.unesp.br

Received 26 D ecember 2001

A ccepted 13 M ay 2002
Venomous A nimals, of São Paulo State University, from O ctober 2000 to J anuary 2001. The animals were checked for the presence of oocysts of Cryptosporidium sp. at the time of arrival and 30 and 60 days later. Data concerning snake collection (origin, place, and date), biometry (total length and weight), and sex were recorded immediately after the arrival of each animal.

Intestinal washings with saline solution ( $1 \%$ body weight) were performed on three occasions during the study. The collected samples were centrifuged and the sediment stored in $10 \%$ buffered formalin. Cryptosporidium oocysts were concentrated by an ether-phosphate-buffered saline sedimentation technique and then separated by a density gradient centrifugation technique (Waldman et al. 1986). Smears were performed with the sediment and stained by a modified acid-fast and auraminerhodamine method (Henriksen \& Pohlenz 1981). Cryptosporidium-positive smears were used as a control to the experimental findings.

Fecal samples were collected throughout the study and eval uated by the same methodology. Organ scrapings from animals that died were also examined.

The data obtained for the length and weight of the animals at the different times of study were analyzed statistically by the Friedman test. The numbers of males and females were analyzed by the proportion test. The level of significance was set at $5 \%$. Statistical analysis was performed using the Sigma Stat 2.0 software (J andel Cientific Corporation).

\section{RESULTS}

Characterization of the snake population - Fifty snakes were examined. B otucatu (15\%) and Santa M aria da Serra $(13 \%)$ were the towns that donated the largest number of snakes. The proportion of males $(46 \%)$ and 
females (54\%) was similar ( $p>0.05)$. Length and weight measured at 0,30 and 60 days $(82.5 \pm 14.3 \mathrm{~cm}$ versus 82.7 $\pm 14.2 \mathrm{~cm}$ versus $83 \pm 14.1 \mathrm{~cm}$, and $374.8 \pm 234.8 \mathrm{~g}$ versus $361.3 \pm 223.1 \mathrm{~g}$ versus $350 \pm 197.1 \mathrm{~g}$, respectively) did not differ significantly $(p>0.05)$.

Prevalence of infection with Cryptosporidium $\mathrm{sp}$. oocysts - To determine the prevalence of $\mathrm{C}$ ryptosporidium sp. infection we studied 150 samples of intestinal washings collected at 0,30 and 60 days; 62 fecal samples collected throughout the experiment; and scrapings collected at autopsy from the windpipe, lungs, esophagus, stomach and intestine.

The overall prevalence of Cryptosporidium sp. oocysts was $14 \%$. A sample was considered to be positive if suspected forms were detected after auraminerhodamine staining later confirmed by acid-fast staining.

A mong the positive snakes, oocysts were detected only in the intestinal washing in two specimens (17 and 21), only in the feces in four (specimens 1, 22, 37 and 49) and in both materials at least once in one specimen (18). The positive snakes were predominantly from Santa M aria da Serra (57.1\%). We also observed that all of the examinations giving positive results were those made at least 27 days after the capture of the animals (Table).

\section{DISCUSSION}

We believe that the infection-rate of $14 \%$ in our snakes was underestimated due to the techniques employed. Detection of anti-Cryptosporidium antibodies in serum, as well as antigens in the feces of snakes, have shown a respective prevalence of $73 \%$ and $89 \%$ (Graczyk \& Cranfield 1997).

The current literature shows that the fecal smear technique is not the best method for the diagnosis of cryptosporidiosis, even more so when the infection is subclinical. This technique should be used exclusively for the determination of Cryptosporidium-positive snakes and not for the diagnosis of negativity. Even multiple, subsequent negative smears cannot be used as the basis for any conclusion regarding infection with Cryptosporidium (Graczyk et al. 1995, 1996c). O ur concentration technique permits larger amounts of feces or intestinal washings to be analyzed. It has been shown that feces that do not represent at least $0.41 \%$ of the body weight of the snake present low oocyst numbers, resulting in concentrations below detectable levels in a single smear (Graczyk etal. 1995).

Disproportion in the mass of feces is a characteristic of the physiology of the digestive tract of snakes (G raczyk et al. 1995). Food retention and infrequent defecation are normal for these animals and are not associated with any abnormalities or with health (Graczyk et al. 1996c). The food can stay in the intestine for variable periods of time, and the number of defecations is not the same as the number of food intakes. The cloaca of the snake serves as a place of passage or stockpiling for feces and urine. Thus, in fecal samples of small weight, the urine constitutes a large proportion compared to fecal samples of high weight. This can explain the low concentration of oocysts in fecal samples of low weight (G raczyk et al. 1995).

This explanation is also valid for the intestinal washing. We noted that in some cases there was only mucus and no fecal content after washing of the mucous membrane, or even a large urate concentration. This resulted in a low oocyst concentration. For this reason, we decided to centrifuge the samples.

The literature shows that elimination of oocysts in the feces is periodic (Graczyc et al. 1996c), explaining the presence or absence of oocysts in samples from the same animal. The presence of Cryptosporidium sp. can be frequently associated with capture or recent import, suggesting that stress and altered immunological state can play an important role in the development of the infection (F ayer \& U ngar 1986, Gillespie 1988, O'D onoghue 1995, Tzipori \& G riffiths 1998). Cryptosporidiosis is selflimited in immunocompetent mammals and a life threat in immunosuppressed mammals, and this seems to also be true for reptiles. The elimination of environmental or nutritional problems and other diseases seems to be more effective than the use of anti-Cryptosporidium drugs to reduce the infection (Graczyc et al. 1996a).

The stress of captivity may have contributed to induce elimination of oocysts in the feces and intestinal washing in our snakes, a fact that would explain the detection of positive samples during the second examination of our study (30th day). When we specifically analyzed animal

TABLE

Origin, capture, sex and examinations of snakes positive for C ryptosporidium sp.

\begin{tabular}{clccccc}
\hline N r. & Origin & Capture date & Arrival date & Sex & $\begin{array}{c}\text { Date of postive exam } \\
\text { (days after capture) }\end{array}$ & Sample \\
\hline 1 & Pratânia & $\mathrm{NI}$ & $11 / 01 / 2000$ & $\mathrm{M}$ & $12 / 09 / 2000$ (39th day) & $\mathrm{FE}$ \\
17 & Santa M aria da Serra & $11 / 14 / 2000$ & $11 / 17 / 2000$ & $\mathrm{~F}$ & $12 / 26 / 2000$ (42th day) & IW \\
& & & & & $01 / 29 / 2001$ (76th day) & IW \\
18 & Itaberá & $10 / 30 / 2000$ & $11 / 20 / 2000$ & $\mathrm{~F}$ & $11 / 27 / 2000$ (28th day) & $\mathrm{FE}$ \\
& & & & $12 / 26 / 2000$ (57th day) & IW \\
& & & & $01 / 29 / 2001$ (91th day) & IW \\
& & & & $02 / 16 / 2001$ (109th day) & $\mathrm{FE}$ \\
21 & Santa M aria da Serra & $11 / 29 / 2000$ & $11 / 29 / 2000$ & $\mathrm{~F}$ & $12 / 26 / 2000$ (27th day) & IW \\
22 & Santa M aria da Serra & $11 / 29 / 2000$ & $11 / 29 / 2000$ & $\mathrm{~F}$ & $01 / 24 / 2001$ (56th day) & $\mathrm{FE}$ \\
37 & Santa M aria da Serra & $12 / 28 / 2000$ & $01 / 02 / 2001$ & $\mathrm{M}$ & $01 / 24 / 2001$ (27th day) & $\mathrm{FE}$ \\
49 & A nhembi & $01 / 21 / 2001$ & $01 / 30 / 2001$ & $\mathrm{M}$ & $02 / 22 / 2001$ (30th day) & $\mathrm{FE}$ \\
\hline
\end{tabular}

$\mathrm{NI}$ : no information from donor; $\mathrm{M}$ : male; $\mathrm{F}$ : female; $\mathrm{FE}$ : feces; IW : intestinal washing 
18 , which had presented positive results only 7 days after its arrival at the Center; we observed that this animal had been captured 20 days before. Therefore, $100 \%$ of the samples studied, including feces or intestinal washings, were positive commencing from the 27th day after the animal's capture in its natural environment.

Our results confirm the characteristic of intermittent elimination of oocysts (Graczyc et al. 1996c). A nimal 1 gave a negative result for oocysts in the three intestinal washings, but the fecal samples were positive on the 38th day. A nother fecal examination performed 6 days later gave a negative result. A nimal 17 presented positive intestinal washings at 30 and 60 days, but negative fecal examinations. The first intestinal washing of animal 18 was negative for Cryptosporidium sp. 0ocysts, while 7 days later, the fecal sample was positive. None of the snakes studied showed clinical signs of infection with Cryptosporidium sp.

Captive snakes are maintained on a diet of rodents, birds or mammals. It seems unlikely that infection is by way of the prey, however, because a comparison of the biology of Cryptosporidium from reptiles and mammals suggests that they represent different species (Fayer et al. 1995, Graczyk et al. 1996, G raczyk \& Cranfield 1998, Graczyk et al. 1998a,b), and that cross-transmission experiments do not produce infections (Fayer et al. 1995, G raczyk etal. 1996, 1998, Graczyk \& Cranfield 1998). Thus, Cryptosporidium oocysts isolated from snakes are not transmissible to birds or rodents ( $\mathrm{Graczyk} \&$ Cranfield 1997) and probably, therefore, not to man.

It is important nevertheless to recognize that the infected prey can be a source of oocysts which are ingested by the snake and undergo a passive oocyst transfer through the intestine. Although there is no infection, these animals can then eliminate oocysts that are detected in the feces (Graczyk \& Cranfield 1997). A Ithough some minimal differences have been reported in the size of Cryptosporidium sp. oocysts of snakes and mammals, it is impossible to differentiate them using only morphology (Graczyk \& Cranfield 1997). This means that snakes that el iminate oocysts may not actual ly be infected by Cryptosporidium sp. In our study, tests were not performed for the presence of oocysts in the mice used to feed the snakes. However, we observed the presence of oocysts in snakes that had both fed and not fed on such animals. In addition, most of the animals that did feed did not present 0ocysts. All this suggests that the oocysts detected in our snakes were acquired under natural conditions. Finally, molecular studies will probably prove to be useful in the identification of Cryptosporidium species.

\section{REFERENCES}

Cranfield M R, Graczyk TK 1996. Cryptosporidiosis. In DR M ader, Reptile Medicine and Surgery, W B Saunders, Philadelphia, p. 359-363.
Fayer R, Ungar BLP 1986. Cryptosporidium spp. and cryptosporidiosis. M icrobiol Rev 50: 458-483.

Fayer R, Graczyk TK, Cranfield M R 1995. Multiple heterogeneous isolates of $C$ ryptosporidium serpentis from captives snakes are not transmissible to neonatal BA L B/c mice (M us musculus). J Parasitol 81: 482-484.

Gillespie D 1988. Criptosporidiosis em répteis. In RW Kirk, Atualização Terapêutica Veterinária, Vol. 2, Manole, Rio de J aneiro, p. 941-942.

Graczyk TK, Cranfield MR 1996. Assessment of the conventional detection of fecal Cryptosporidium serpentis oocysts in subclinically infected captive snakes. Vet Res 27 : 185-192.

Graczyk TK, Cranfield M R 1997. Detection of Cryptosporidium-specific serum immunoglobulins in captive snakes by a polyclonal antibody in the direct Elisa. Vet Res 28: 131142.

Graczyk TK, Cranfield M R 1998. Experimental transmission of Cryptosporidium oocyst isolates from mammals, birds and reptiles to captive snakes. Vet Res 29: 187-195.

Graczyk TK, Cranfield MR, Fayer R 1995. A comparative assessment of direct fluorescence antibody modified acid fast stain, and sucrose flotation techniques for detection of Cryptosporidium serpentis oocysts in snakes fecal specimens. J Zoo Wildl M ed 26: 396-402.

Graczyk TK, Cranfield M R, Fayer R 1998a. Oocysts of Cryptosporidium from snakes are not infectious to ducklings but retain viability after intestinal passage through a refractory host. Vet Parasitol 77: 33-40.

Graczyk TK, Cranfield MR, Geitner MEA 1998b. Multiple Cryptosporidium serpentis oocyst isolates from captives snakes are not transmissible to amphibians. J Parasitol 84: 1298-1300.

Graczyk TK, Cranfield M R, Helmer P, Fayer R, B ostwick E F 1998c. Therapeutic efficacy of hyperimmune bovine colostrum treatment against clinical and subclinical Cryptosporidium serpentis infections in captives snakes. Vet $P$ arasitol 74: 123-132.

Graczyk TK, Cranfield M R, Hill SL 1996a. Therapeutic efficacy of hal ofuginone and spiramycin treatment against Cryptosporidium serpentis (A picomplexa: Cryptosporidiidae) infections in captives snakes. P arasitol Res 82: 143-148.

Graczyk TK, Fayer R, Cranfield M R 1996b. Cryptosporidium parvum is not transmissible to fish, amphibians, or reptiles. J Parasitol 85: 748-751.

Graczyk TK, Owens R, Cranfield MR 1996c. Diagnosis of subclinical cryptosporidiosis in captive snakes based on stomach lavage and cloacal sampling. Vet Parasitol 67: 143151.

Henriksen A, Pohlenz J FL 1981. Staining of C ryptosporidium by a modified Ziehl-Neelsen technique. Acta Vet Scand 22: 594-596.

O'D onoghue PJ 1995. Cryptosporidium and cryptosporidiosis in man and animals. Int J Parasitol 25: 139-195.

Tzipori S, Griffiths JK 1998. Natural history and biology of Cryptosporidium parvum. Adv Parasitol 40: 5-36.

Waldman E, Tzipori S, Forsyth JRL 1986. Separation of Cryptosporidium species oocysts from feces by using a percoll discontinuous density gradient. J Clin Microb 23: 199-200. 
